\title{
BMJ Global Health Availability and provision of emergency obstetric care under a public-private partnership in three districts of Gujarat, India: lessons for Universal Health Coverage
}

\author{
V lyer, ${ }^{1} \mathrm{~K}$ Sidney, ${ }^{2} \mathrm{R}$ Mehta, ${ }^{3} \mathrm{D}$ Mavalankar ${ }^{1}$
}

To cite: Iyer V, Sidney K, Mehta $\mathrm{R}$, et al. Availability and provision of emergency obstetric care under a publicprivate partnership in three districts of Gujarat, India: lessons for Universal Health Coverage. BMJ Global Health 2016;1:e000019. doi:10.1136/bmjgh-2015000019

- Additional material is available. To view please visit the journal (http://dx.doi.org/ 10.1136/bmjgh-2015000019).

Received 5 December 2015 Revised 19 February 2016 Accepted 22 February 2016

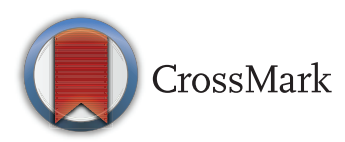

${ }^{1}$ Indian Institute of Public Health Gandhinagar, Public Health Foundation of India, Ahmedabad, Gujarat, India 2Department of Public Health Sciences, Researcher, Karolinska Institutet, Global Health/IHCAR, Stockholm, Sweden

${ }^{3}$ Department of Preventive and Social Medicine, GMERS Valsad Medical College, Valsad, Gujarat, India

Correspondence to Dr V Iyer; veenaiyer@iiphg.org

\section{ABSTRACT}

Objective: The state of Gujarat in India (population 60 million) has implemented a public-private partnership (PPP) with private obstetricians called the Chiranjeevi Yojana (CY) since 2006. This study investigated the adequacy of basic and comprehensive emergency obstetric care (BEmOC and CEmOC) services through the public and private sectors with reference to the United Nations (UN) guidelines.

Design: A cross-sectional facility survey was conducted in three districts.

Results: A total of 300 facilities, 151 public and 149 private, had provided obstetric services to a total of 53896 births in the past 6 months. Nearly half, 135 facilities (104 public and 31 private), individually reported $<10$ births per month (low load), and, as a group, reported only $4 \%$ of all births in the past 6 months. The remaining 165 high-load facilities consisted of 23 (3 public; 20 private) full CEmOC, 66 $(1 ; 65)$ 'potential' CEmOC, $12(3 ; 9)$ BEmOC and 57 $(40 ; 17)$ non-EmOC facilities. All the three districts exceeded the UN recommendation for EmOC availability by 3.3 to 11.3 times. Free provision, through both public and PPP facilities, ranged from 1.42 to 3.43 . The actual performance was nearly double the recommendation for $\mathrm{CEmOC}$ but inadequate for BEmOC.

Conclusions: Public sector EmOC availability and provision is negligible. Private sector availability is well beyond the recommended UN norms. The CY programme has resulted in increased availability and provision of EmOC services. However, the overall provision of $\mathrm{EmOC}$ is compromised due to the poor performance of $\mathrm{BEmOC}$ functions and clustering of private facilities in towns.

\section{BACKGROUND}

The latest global estimates show that 289000 maternal deaths occurred across the world in 2013. Although India has recorded a $65 \%$ decrease in maternal mortality rate (MMR) from 1990 to 2013, it still contributed the

\section{Key questions}

What is already known about this subject?

- Maternal mortality can be reduced by making 7 basic and 2 comprehensive emergency obstetric signal functions accessible to all women in the intrapartum period.

- Since the private sector is now the main provider of health care in most LMICs and MICs, public-private-partnerships can make these services accessible to the neediest populations.

What are the new findings?

- In three less developed districts of Gujarat, while availability and performance of comprehensive obstetric signal functions through the public sector was negligible, that through the private sector was plentiful, 3 to 11 times more than recommended standards.

- Performance of basic signal functions was only $30 \%$ of recommended standard.

- $80 \%$ of private facilities were clustered in $30 \%$ of the towns in the three districts.

Recommendations for policy

- Public-private-partnerships need to ensure appropriate use of basic signal functions.

- There is a need for national policies to better distribute facilities geographically for better access.

- Monitoring and evaluation guidelines for emergency obstetric care need to include indicators to address these issues.

largest proportion, (17\%; 50000 deaths) of maternal deaths in the world in $2013 .{ }^{1}$

The unpredictability of many direct obstetric complications which cause maternal mortality means that they present as emergency situations during the intrapartum period. ${ }^{2}$ Access to interventions targeted at this intrapartum period is crucial to saving maternal lives and reducing mortality. The WHO, UNICEF and United Nations Population 
Fund (UNFPA) have classified these interventions into emergency obstetric care (EmOC) signal functionsseven basic (BEmOC) and two comprehensive (CEmOC). ${ }^{\text {i }} 34$ Whereas it is recognised that all these EmOC functions may be performed by a physician, nurse or midwife, all of whom are defined as skilled birth attendants, the advanced CEmOC function of caesarean section (CS) generally lies in the domain of obstetricians. ${ }^{5}$ In India in particular, BEmOC skills have also become largely concentrated in the hands of obstetricians due to the neglect of the midwifery cadre over the past many decades. ${ }^{6} 7$

Universal Health Coverage (UHC) for all has been set as one of the sustainable development goals the world wishes to attain by $2030 .{ }^{8}$ Universal access to health services, in all its three dimensions, physical accessibility, financial affordability and services acceptability, is a prerequisite for Universal Coverage. Universal Coverage would build on access by ensuring actual receipt of services. ${ }^{9}$ The private sector's rapidly increasing share in meeting the obstetric needs of many countries in Asia, Africa and South America, alongside the lack of information about them, has been well recognised. ${ }^{10}$ At the same time, public provision of EmOC is known to be weak in many LMICs of the world. ${ }^{11}$ Therefore, publicprivate partnerships (PPPs) provide a pragmatic opportunity to bridge the gap in universal access to EmOC by addressing all three dimensions of access.

Gujarat is a large province of 60 million people on India's western flank. In 2005, 43.5\% of births in Gujarat happened at home and the MMR was 160/100 000 births. ${ }^{12} 13$ Owing to lack of obstetricians in the public sector, the state health authorities embarked on a PPP in 2006, called the Chiranjeevi Yojana (CY, meaning 'long-life programme'), with private obstetricians. Its objective was to increase the availability of EmOC services for the poorest families. ${ }^{14}$

Nearly a million births have happened under this CY programme in Gujarat to date (HMIS Reports, Department of Health and Family Welfare, Government of Gujarat, 2014). There has thus far been no information on the extent of private provision of EmOC services in the state. This information is particularly relevant given the recent focus on UHC in the world and in India, ${ }^{15} 16$ and the prominent role of PPPs in gaining access to care. This study investigated the physical accessibility of EmOC in the CY context. Evans et al describe this 'as the availability of good health services within reasonable reach of those who need them and of opening hours, appointment systems and other aspects of service organization and delivery that allow people to obtain the services when they need them'. ${ }^{8}$ We assessed the

${ }^{\mathrm{i} S e v e n ~ b a s i c ~ s i g n a l ~ f u n c t i o n s ~ a r e-i n j e c t a b l e ~ a n t i b i o t i c s, ~ i n j e c t a b l e ~}$ uterotonics, injectable anticonvulsants, manual removal of placenta, removal of retained products, assisted vaginal delivery, neonatal resuscitation; and 2 comprehensive signal functions are caesarean section and blood transfusions.
EmOC services organisation and delivery by (1) assessing the extent of EmOC availability in the public and private sectors and (2) its free provision through the public facilities and CY programme. We investigated the 'goodness' of services at the individual facility level and at the population level by assessing the adequacy of EmOC against the WHO/UNICEF/UNFPA recommended standards for signal functions and population coverage, respectively, ${ }^{4}$ and 'reasonable reach' of these services by mapping the geographical distribution of 'good' EmOC facilities across the three districts.

\section{METHODS}

\section{Study setting}

The state of Gujarat is composed of 26 districts, the average population of a district being 2 million. Districts are further divided into blocks (subdistricts), about 225 in number, each with an approximate population of 100 000-200 000. Fifty-seven per cent of the population of Gujarat is rural.

\section{CY programme}

In 2005, obstetric care in the state was available in public and private health sectors. Public provision, though free of charge at the point of care, was ineffective due to its inability to provide EmOC services, especially in rural areas. Out of more than 2000 obstetricians practising in the state, only 8 served in public subdistrict level hospitals in rural areas. Others practised privately, many of them located in semiurban areas. In order to reduce financial access barriers to EmOC care for the poorest and neediest women, the state health authorities embarked on a PPP with private obstetricians in the state. MD and/or diploma qualified obstetricians were invited to partner in the programme if they possessed functioning nursing homes with labour and operating rooms and the ability to perform EmOC functions, such as treating eclampsia and postpartum infection and performing assisted vaginal deliveries, CS and blood transfusions. Around 865 obstetricians enrolled into the scheme in 2006-2007. Each was paid US $\$ 4500$ for a package of 100 deliveries-85 normal and 15 complicated (8 requiring some non-surgical EmOC intervention and 7 requiring CS $)^{17}$ - of mothers from Below Poverty Line or Scheduled Tribe households (BPL/ST). ${ }^{\text {ii }}$ The terms of this CY payment package reflected the principle behind indicator 3 of the WHO/UNICEF/UNFPA guidelines of 1997 , that is, $15 \%$ of all childbirths would require obstetric intervention and therefore hospitalisation.

\footnotetext{
ii The poverty line is an economic threshold set by the government of India, based on a survey which scores household assets to indicate households targeted for social welfare programs. Those with scores from 0 to 16 are eligible for the Chiranjeevi programme. Scheduled tribes are specially recognised by the Indian constitution as disadvantaged groups in the country and constitute $\sim 7.5 \%$ of India's population. These lists are regularly updated by the government and are used for government schemes.
} 


\section{Study districts}

Three heterogeneous districts, with an average population of 2 million, were purposively selected. Out of the districts with human development indices among the lowest $30 \%$ of districts in the state, $^{18}$ we selected Surendranagar, Sabarkantha and Dahod, with variations in geographic location (western, central and eastern belts), ${ }^{19}$ and sociodemographic characteristics (proportion tribal and birth rates). Table 1 depicts relevant demographic details of the three selected study districts.

\section{Data collection}

\section{Listing phase}

We obtained a list of all public facilities which are officially supposed to conduct childbirths ${ }^{23} 24$ from the state health department's website and a list of private facilities from the state chapter of the Federation of Obstetric and Gynaecological Societies of India. This master list was complemented in the field by snowballing techniques. All private and public obstetric facilities in the master list and private pharmacies in the study districts were asked to identify all facilities in their neighbourhood which had conducted any childbirths in the last 1 year. Eligible facilities were added to the list and further snowballing was done throughout the listing and survey phases until no more new facilities could be identified. We administered an initial short screening questionnaire which enquired whether any childbirths had been conducted in the last 1 year. In case there had been any, the surveyor recorded the number of births in the past 3 months and whether the facility was a current CY participant.

\section{Survey phase}

We visited all the listed public and private facilities between June 2012 and April 2013. Twenty surveyors, comprising qualified nurses, medical social workers and doctors of traditional medicine, were trained to administer the questionnaires and carry out field supervision.
We modified the Averting Maternal Death and Disability (AMDD) questionnaires to include relevant indicators from the Monitoring emergency obstetric care: a handbook ${ }^{4}$ and administered these to all facilities which had conducted any childbirth in the past 3 months.

The delivery room nurse or obstetrician provided information pertaining to participation in $\mathrm{CY}$ and actual performance of the nine EmOC signal functions and reasons for non-performance in the 3 months before the survey. Clerical and paramedical staff responded to questions pertaining to physical characteristics of the facilities like their age, location and bed strength. Availability of qualified obstetrician $24 \times 7$, supplies, functional equipment and trained staff were also confirmed. Study instruments were pilot tested and revised prior to implementation of the main study. All forms were checked by field supervisors in the district. Surveyors in the field were supervised by senior project staff during field data collection.

Study instruments were pilot tested and revised prior to implementation of the main study. All forms were checked by field supervisors in the district. Surveyors in the field were supervised by senior project staff during field data collection.

\section{Analysis}

Data were entered into and subsequently extracted from the Research Electronic Data Capture (REDCap) database and analysed using Stata (V.12.0, StataCorp). We compared EmOC availability in each district against recommended standards. We also conducted a Pareto analysis of the distribution of EmOC facilities.

Ethical approval for this study was obtained from the institutional review board at Indian Institute of Public Health Gandhinagar (TRC-IEC No. 23/2012).

\section{RESULTS}

Our initial list of 1145 public and 76 private facilities in June 2012 was completed using the snowballing exercise

Table 1 Profile of study districts

\begin{tabular}{|c|c|c|c|c|c|c|c|}
\hline & $\begin{array}{l}\text { Population } \\
\text { (in millions) }^{20}\end{array}$ & $\begin{array}{l}\text { Birth } \\
\text { Rate } \\
\text { per } \\
1000^{21}\end{array}$ & $\begin{array}{l}\text { Proportion } \\
\text { rural }(\%)^{20}\end{array}$ & $\begin{array}{l}\text { Proportion } \\
\text { ST }(\%)^{20}\end{array}$ & $\begin{array}{l}\text { Proportion } \\
\text { BPL (\%) }{ }^{22}\end{array}$ & $\begin{array}{l}\text { Proportion } \\
\text { eligible for CY } \\
\text { benefit-(BPL } \\
+ \text { ST) }(\%)^{2022}\end{array}$ & $\begin{array}{l}\text { Proportion of } \\
\text { total registered } \\
\text { deliveries } \\
\text { conducted under } \\
\text { Chiranjeevi in } \\
2006-2011(\%)^{\star}\end{array}$ \\
\hline Gujarat state & 60.4 & 22.7 & 57 & 14.8 & 39.6 & 40.7 & 10.9 \\
\hline $\begin{array}{l}\text { Surendranagar } \\
\text { district }\end{array}$ & 1.75 & 23 & 72 & 0.92 & 46.5 & 45.4 & 10.1 \\
\hline $\begin{array}{l}\text { Sabarkantha } \\
\text { district }\end{array}$ & 2.43 & 28 & 85 & 20.2 & 32.9 & 43.3 & 22.0 \\
\hline Dahod district & 2.12 & 30.2 & 90 & 72.4 & 71.6 & 87.9 & 29.7 \\
\hline
\end{tabular}

*HMIS Reports. 2006-2011 Department of Health and Family Welfare, Government of Gujarat. 2012.

BPL, Below Poverty Line; CY, Chiranjeevi Yojana; ST, Scheduled Tribe. 
in the field and culminated with a final list of 1149 public and 151 private facilities. The snowballing exercise yielded $50 \%$ of the final tally of private facilities.

Among the 1149 public facilities officially supposed to conduct childbirths, only $13 \%$ (151) reported that they had actually conducted any childbirth in the previous 3 months (table 2). Among private facilities, 98.6\% (149) had conducted a childbirth in the previous 3 months. These summed to 300 facilities which had conducted 29482 births in the past 3 months. The majority of these, $95.6 \%$, were in 165 facilities which conducted $>30$ deliveries in the past 3 months-highload facilities (detailed flow chart of facility distribution in online supplementary figure S1).

\section{Extent of EmOC availability and provision in the public and private sectors}

EmOC availability and provision ensued predominantly through the 165 high-load facilities, 47 public and 111 (7 refusals) private facilities. (Capacity of each facility group to provide each of the EmOC functions is shown in online supplementary figure S2; availability and provision of EmOC through high and low load facilities has been shown in online supplementary tables S1a, b.)

Only 6 of the 47 high-load public facilities had a qualified obstetrician on call $24 \mathrm{~h}$ of the day and thus the capacity to provide all nine EmOC functions; of these, only 3 (2 district and 1 subdistrict hospitals) had actually performed all the functions in the past 3 months (figure 1). One (district hospital) had performed CS

Table 2 Number of facilities and self-reported births in the past 3 months in public and private sectors in the three study districts

\begin{tabular}{llrl}
\hline Facilities and births & Public & Private & Total \\
\hline $\begin{array}{l}\text { Number of facilities } \\
\text { identified in the survey }\end{array}$ & 1149 & 151 & 1300 \\
$\begin{array}{l}\text { Number of facilities } \\
\text { conducting any } \\
\text { childbirth in the last } \\
1 \text { year }\end{array}$ & 151 & 149 & 300 \\
$\begin{array}{l}\text { Total childbirths } \\
\text { conducted }\end{array}$ & 9031 & 20451 & 29482 (100\%) \\
$\begin{array}{l}\text { Number of facilities } \\
\text { conducting <30 births in } \\
\text { the past } 3 \text { months (low } \\
\text { load) }\end{array}$ & 104 & 31 & 135 \\
$\begin{array}{l}\text { Number of births } \\
\text { conducted in the past } \\
3 \text { months (low load) }\end{array}$ & 886 & 363 & $1249(4.4 \%)$ \\
$\begin{array}{l}\text { Number of facilities } \\
\text { conducting }>30 \text { births in } \\
\text { the past } 3 \text { months (high } \\
\text { load) }\end{array}$ & 47 & 118 & 165 \\
$\begin{array}{l}\text { Number of births } \\
\text { conducted in the past } \\
3 \text { months (high load) }\end{array}$ & 8145 & 20088 & 28233 (95.6\%) \\
\hline
\end{tabular}

and blood transfusion, but this facility reported not performing three or more BEmOC functions in the past 3 months because it did not receive a patient requiring those BEmOC services. We treated this as a 'potential' EmOC facility since this cause was not correctable within the facility. Adding up the 'performed' and 'potential' facilities gave us four 'able' public sector facilities. Two other facilities did not perform BEmOC/CEmOC functions consistently due to management, policy and training issues, mainly due to the unreliable availability of the obstetrician. Such facilities were treated as 'non-EmOC'.

Among the 118 high-load private facilities, 93 had the capacity to perform all nine EmOC functions. While 20 of them had actually performed all nine EmOC functions, 65 'potential' had performed CS and blood transfusions but had not performed 1-4 of the BEmOC functions, either singly or in combination. This too was because they had not received any patient presenting with indications for performance of these signal functions, a reason not correctable within the facility. The BEmOC functions that they did not perform were in the following order of frequency-manual removal of placenta (39/65), administration of anticonvulsants $(22 / 65)$, assisted vaginal delivery $(16 / 65)$, neonatal resuscitation $(8 / 65)$ or removal of retained products $(7 / 65)$ (detailed in online supplementary table S2). Thus, we had 85 'able' private facilities.

However, eight facilities had not performed BEmOC and/or CEmOC functions due to policy, management and training issues that would need corrections at the facility level. These were treated as 'non-EmOC' facilities.

Therefore, considering both the public and private sectors together, availability of CEmOC was through 89 facilities which were 'able' to perform nine CEmOC functions-66 'potential' and 23 actually 'performed' facilities. However, free provision was through only 39 facilities, 4 public and 35 private CY participant facilities.

\section{EmOC coverage in comparison to United Nations (UN) recommendations}

In order to compare against the UN recommended standards, we considered the 89 'able' EmOC facilities and the subset of 23 'performed' EmOC facilities.

Public EmOC provision of 'able' facilities was well below recommended standards, only 4 against the required 13 facilities, that is, only 0.32 against the required 1 for every 500000 population (table 3). However, on adding the 85 private 'able' EmOC facilities, EmOC availability increased to 7.06 times more than the recommended standard of 1 for CEmOC. It was also 2.06 units more than the recommended standard of 5 for BEmOCs and CEmOCs together. Actual 'performance' of all CEmOC functions by 23 facilities, at 1.82 , was nearly double the recommended standard.

Private 'able' EmOC provision (CY and non-CY) exceeded the recommended UN norms for EmOC in all 


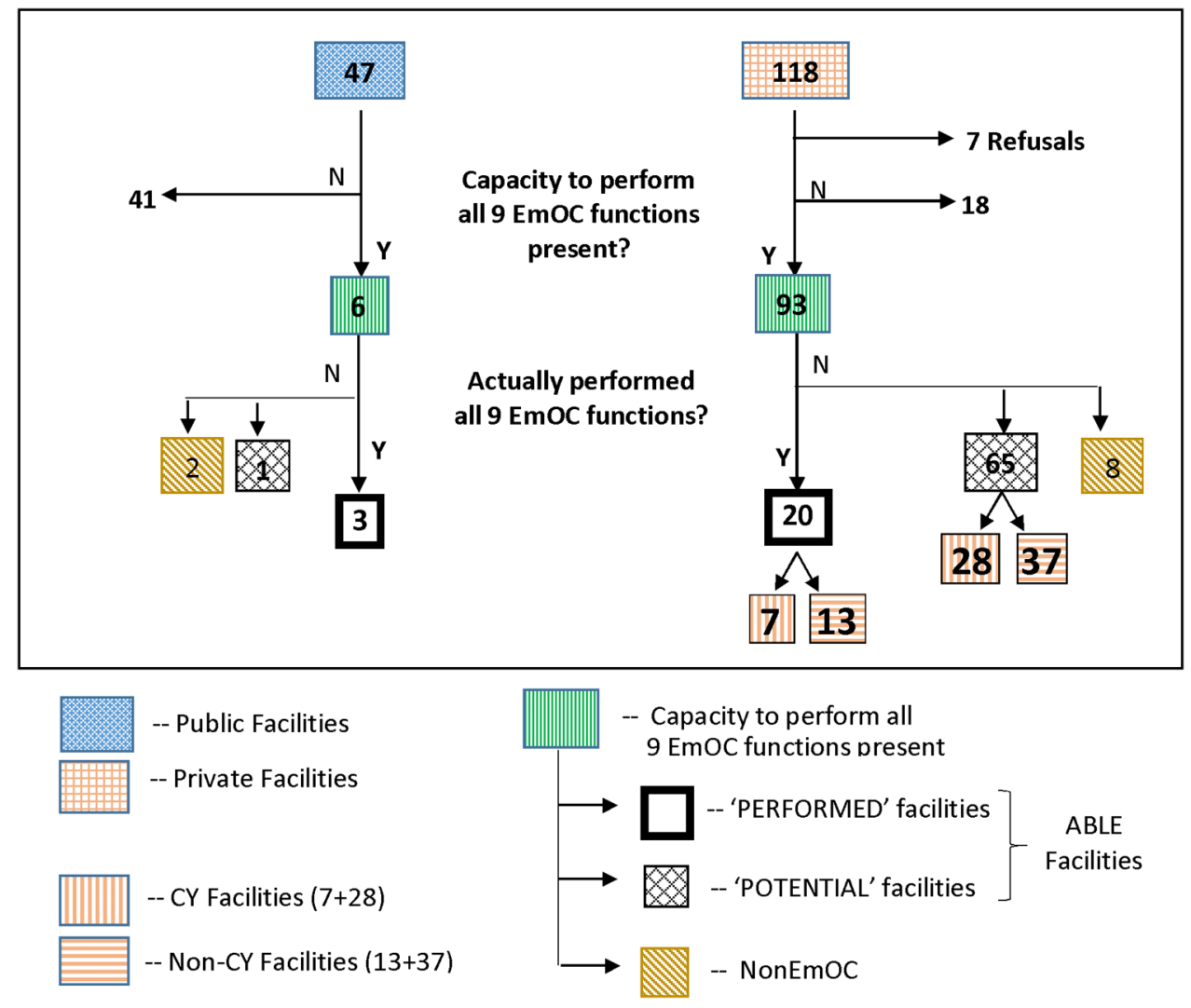

Figure 1 Flow chart showing the classification of high-load facilities into 'performed' in the past 3 months, 'potential' and non-EmOC facilities. ('Able' EmOC facilities consist of 'performed' and 'potential' facilities.) CY, Chiranjeevi Yojana; EmOC, emergency obstetric care.

three districts. Surendranagar and Sabarkantha districts had 'able' CEmOC availability well above recommended standards at 5.43 and 10.9, respectively. The tribal district of Dahod had the least 'ability', but even this was more than double the recommended standard at 3.3.

In terms of actual performance of CEmOC functions in the past 3 months, Dahod had achieved the recommended standard at 1.18 and Sabarkantha, with 3.09, had performed three times better than the recommended standard; Surendranagar, with 0.86, had performed less than the expected standard.

Although the 'ability' to provide purely BEmOC services at 0.47 was less than the recommended standard at 5, CEmOC facilities with the ability to provide all BEmOC functions more than made up for this.

Given that the government has attempted to increase the availability of free CEmOC under the CY programme, CEmOC paid for by the state comprises public plus participating private CY facilities. Overall, in the three districts, the 35 facilities participating in the CY programme raised the free CEmOC availability in the three districts from 4 to 39 facilities, that is, from 0.32 to 3.09 times the recommended standard. However, this remained short of the recommended BEmOC availability of 5. Similarly, free provision of EmOC through public and CY facilities which actually 'performed' all EmOC functions was below the recommended standard at 0.79 .

\section{Distribution of CEmOC facilities in the three districts}

As seen in figure 2A, many high-load EmOC facilities were located in close geographic proximity to each other in two towns in Surendranagar, eight towns in Sabarkantha and three towns in Dahod. All three districts also show 2-3 contiguous blocks without any EmOC facility.

The Pareto graph in figure 2B further illustrates this concentration. Eighty per cent of 'able' and 'performed' facilities were located in $30 \%(9 / 30)$ of the towns.

The remaining $70 \%$ of towns had only $20 \%$ of the able facilities and lesser still had performed EmOC functions. Of these 21 towns, 17 were headquarters of blocks which had been categorised among the most backward blocks with composite developmental indices well below state average by the state-level Cowlagi commission in 2004. ${ }^{25}$ Thus, the availability and provision of EmOC care was practically non-existent for the most underdeveloped blocks in the three districts.

\section{DISCUSSION}

\section{Main findings}

Plentiful availability but not as much performance of CEmOC functions

Our study found that availability of EmOC services in the three districts was well above the UN 2009 standards 
Table 3 UN recommended numbers of EmOC facilities in three districts contrasted with actual numbers provided by public and private sector high-load facilities

\begin{tabular}{|c|c|c|c|c|}
\hline Indicator source and availability of facilities & Surendranagar & Sabarkantha & Dahod & Total \\
\hline Population $^{18}$ & 1750000 & 2430000 & 2120000 & 6300000 \\
\hline Births per year ${ }^{19}$ & 40250 & 68040 & 64024 & 172314 \\
\hline \multicolumn{5}{|l|}{ UN handbook 2009 Recommendations for EmOC } \\
\hline Required CEmOC facilities (at least 1 per 500 000) & 4 & 5 & $4-5$ & $13-14$ \\
\hline Required BEMOC+CEmOC facilities (at least 5 per 500000 ) & 18 & 25 & $21-22$ & $64-65$ \\
\hline \multicolumn{5}{|c|}{ Availability of 'able' CEmOC facilities and, among these, 'performed' (in parenthesis) CEmOC facilities } \\
\hline Public CEmOC facilities & $1(1)$ & $2(1)$ & $1(1)$ & $4(3)$ \\
\hline \multicolumn{5}{|l|}{ CEmOC facilities added by private } \\
\hline $\mathrm{CY}$ & $11(0)$ & $19(5)$ & $5(2)$ & $35(7)$ \\
\hline Non-CY & $8(2)$ & $34(9)$ & $8(2)$ & $50(13)$ \\
\hline Total CEmOC facilities added by private & $19(2)$ & $53(14)$ & $13(4)$ & $85(20)$ \\
\hline $\begin{array}{l}\text { Total available 'able' and 'performed' } \\
\text { in the past } 3 \text { months CEmOC facilities }\end{array}$ & $20(3)$ & $54(15)$ & $15(5)$ & $89(23)$ \\
\hline \multicolumn{5}{|c|}{$\begin{array}{l}\text { Availability of 'able' and 'performed' (in parentheses) CEmOC facilities by population norms (against recommended } \\
\text { value of ' } 1 \text { ' for 'CEmOC' and ' } 4+1 \text { ' for 'BEmOC+CEmOC') }\end{array}$} \\
\hline \multicolumn{5}{|c|}{ CEmOC per 500000 population } \\
\hline Public provision & $0.28(0.28)$ & $0.41(0.21)$ & $0.24(0.24)$ & $0.32(0.23)$ \\
\hline Private availability & $5.43(0.57)$ & $10.90(2.89)$ & $3.07(0.94)$ & $6.74(1.59)$ \\
\hline All (public and private) availability & $5.71(0.86)$ & $11.31(3.09)$ & $3.30(1.18)$ & $7.06(1.82)$ \\
\hline Free provision by state and $\mathrm{CY}$ & $3.43(0.28)$ & $4.11(1.23)$ & $1.42(0.71)$ & $3.09(0.79)$ \\
\hline \multicolumn{5}{|l|}{ Availability of BEmOC-only facilities } \\
\hline Total available BEmOC-only facilities & 2 & 3 & 1 & 6 \\
\hline BEmOC-only facilities per 500000 population & 0.57 & 0.61 & 0.23 & 0.47 \\
\hline
\end{tabular}

BEmOC, basic EmOC; CEmOC, comprehensive EmOC; CY, Chiranjeevi Yojana; EmOC, emergency obstetric care; UN, United Nations.

(7.06 times more, table 2) largely because of 'potential' private sector facilities. However, the actual performance of all nine EmOC functions was only around double (1.82) the recommended standard of 1 for CEmOC, but well below 5, recommended for BEmOC. This is similar to findings from less developed Indian states and sub-Saharan African countries, where availability of CEmOC services was 2-3 times more than the recommended standard, but the availability of BEmOC functions, even in combination with CEmOC services, was much less than the recommended standard of $5 .^{10} 2627$ In our setting, the larger availability of BEmOC functions in the private sector did not actually convert into increased performance. Therefore, it appears that in our mixed health system setting, the measurement of BEmOC functions is a more crucial indicator of EmOC functionality since the availability of CS and blood transfusion is plentiful.

Public sector provision of EmOC was negligible, but the CY partnership raised a provision of CEmOC (3.09) but not BEmOC above recommended standards.

Regional variation in EmOC availability

While public availability and provision of EmOC was uniformly low in all districts, there was considerable variation in private EmOC availability. The underdeveloped tribal district of Dahod (table 1) had much lower private EmOC availability than the other two districts. Also, performance of nine CEmOC functions was variable-below, as much as and three times more than the recommended standard in Surendranagar, Dahod and Sabarkantha, respectively.

Increased geographic availability of free $\mathrm{EmOC}$ due to $\mathrm{CY}$ With $40 \%$ participation by eligible EmOC facilities, geographic availability of free EmOC increased from 4 to 16 towns. However, the geographic crowding of these facilities at 16 block level towns meant that EmOC services were concentrated at this level. There were still 9 blocks, 2-3 of them contiguous, in each district, with approximate populations of 500000 or more, which had no private (or public) EmOC providers and therefore no possibility of any PPP.

\section{Strengths and limitations}

This study is a first report that quantifies the size of the private obstetric sector and maps out its spatial distribution. It brings into focus the elements that may be used by authorities for refining and targeting partnerships to get more effective services. 
A
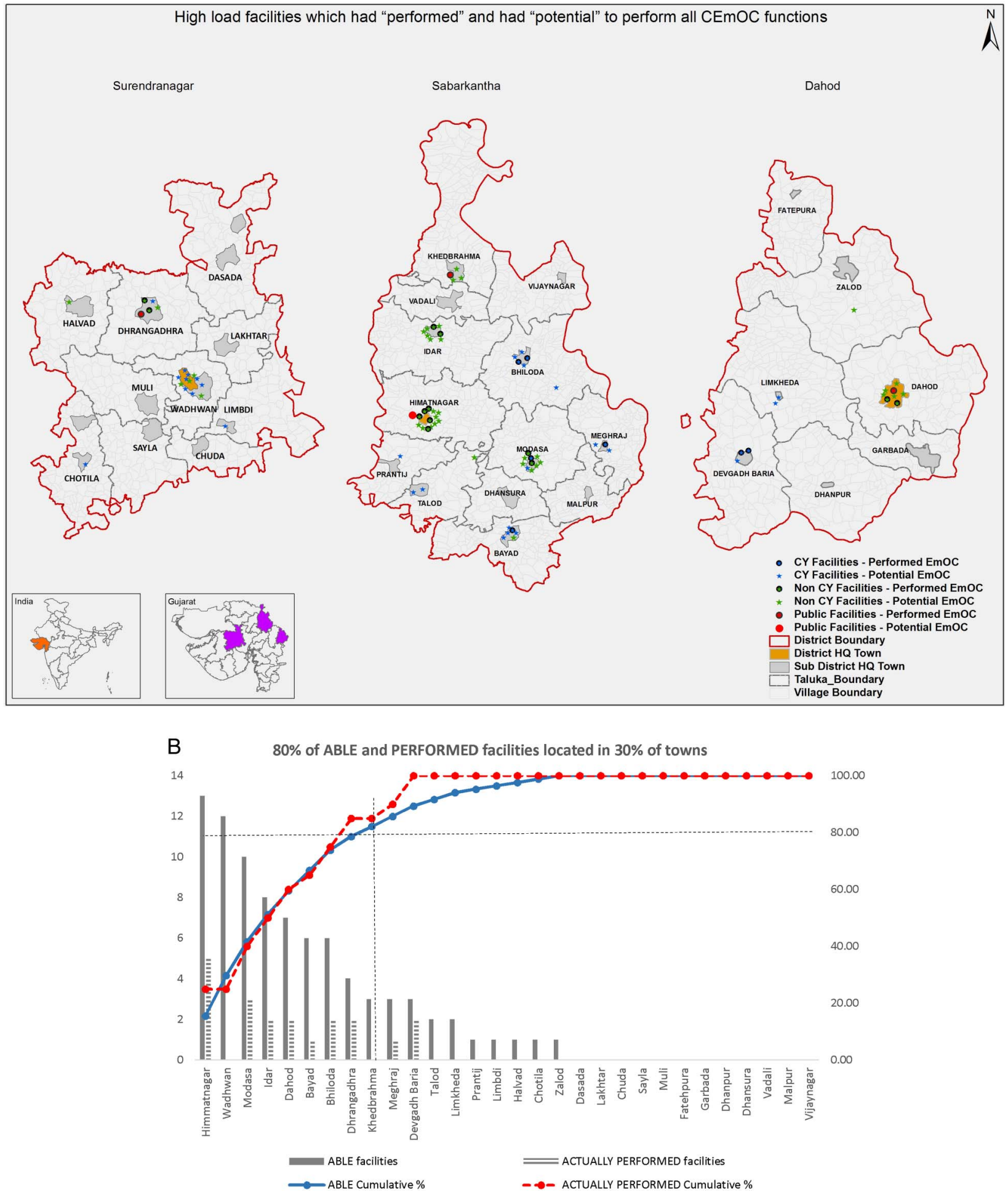

Figure 2 (A) Map showing distribution of 'able' facilities, both 'performed' and 'potential' high-load EmOC facilities in three study districts. (B) Pareto graph showing numbers and cumulative proportion of 'able' and 'performed' facilities in the 30 district/block $\mathrm{HQ}$ towns. CEmOC, comprehensive EmOC; CY, Chiranjeevi Yojana; EmOC, emergency obstetric care; HQ, headquarter.

Our purposive selection of districts was successful in detecting a noteworthy difference in EmOC availability and provision in the three districts which had Human Development Index ranks among the lowest $30 \%$ of districts in the state. Our results may be reasonably generalisable to similar districts with a nearly $80 \%$ rural (and/or tribal) population in the country, especially those in the more developed and urbanised southern and western states of India, which have a larger presence of qualified private obstetricians. ${ }^{28}$ However, the reason 
for the variability in EmOC availability across the study districts is not clear and needs further investigation. While self-reports about the performance of CS and blood transfusions were easily verifiable in facility records, the same was not the case with the BEmOC functions due to poor recording of these functions. Therefore, our categorisation of facilities based on their BEmOC functions are largely based on self-reports by practitioners and hence have their attendant limitations.

Our study has addressed the physical accessibility dimension of EmOC services from the supply perspective, not from the demand perspective.

\section{Implications for UHC}

During the past decade, the formal and informal private sectors have provided obstetric services for more than half of all births in South Asia and sub-Saharan Africa. ${ }^{29}$ One of the three recommended paths of the WHO to financing UHC in the world is the elimination of direct payments for health services. ${ }^{30}$ The proposed plan for UHC in India supports the incorporation of the private sector into an Integrated National Health System, guided by principles of equity enhancement. ${ }^{16}$ This Chiranjeevi partnership in Gujarat incorporates the private sector and eliminates direct payments for obstetric services for the poorest women, as recommended.

The state authorities of Gujarat have, over the past decade, attempted to strengthen emergency obstetric services in the public sector through CEmOC training of general medical officers, ${ }^{31}$ operationalising First Referral Units, ${ }^{32}$ and creating a cadre of Independent Nurse Practitioners for midwifery. ${ }^{33}$ These have not been successful, as seen from our results. Since EmOC is available in the private sector in the state, a more practical solution for the state governments is to buy the services from them. However, the repercussions of availability of BEmOC services only within CEmOC facilities, as in our setting, needs to be factored into the state PPP plan. This pattern of EmOC provision would arguably encourage more usage of CS. Therefore, contracts drawn with private practitioners should refine clauses so as to incentivise judicious usage of BEmOC skills by participant facilities. Also, the state needs to consider financial and human resource investments and policy initiatives to promote BEmOC-only facilities as there is already enough private investment and availability of CEmOC in many urban centres. The adaptation of the third WHO/ UNICEF/UNFPA EmOC indicator in the design of the CY payment package is a commendable beginning. Similarly, planning and monitoring of future PPPs should use this and the remaining seven indicators. Considering that a huge amount of health services are being accessed in private facilities, it is essential that the state and national Health Information Systems be expanded to include the services delivered privately and designed such that they may be assessed against recommended standards.
In the larger countrywide context, the total absence of life-saving services in some areas and their clustering in others indicates the need for a national policy to encourage a more even distribution of life-saving services through the public and private sectors. India needs to build national guidelines based on which district-level authorities may categorise towns and blocks according to the need for particular services or beds, akin to the Certification-of-Need policy in some countries. ${ }^{34} 35$ All future planning for public and private health services could use such a categorisation to set differential pricing or incentive policies based on block-level health service needs. This may be key to help India avoid the pitfalls of regressive disparities on the pathway to quickly attaining population health gains as has been documented in Latin American countries. ${ }^{36}$

There are two factors of global relevance, viz. the presence of a large number of private facilities which had not performed BEmOC functions inspite of having the ability to do so, and their geographic proximity to each other. Inadequate availability and performance of BEmOC functions have been reported from other Asian and African countries. ${ }^{87-39}$ However, the ample availability of BEmOC only within private EmOC facilities and clustering of these facilities in district and block headquarter towns, as seen in this study in Gujarat and other studies in Karnataka and Maharashtra states of India, ${ }^{40}{ }^{41}$ is probably a typical natural progression in the development of complex mixed health systems. In fact, in more urban districts with larger cities, the geographic proximity of many EmOC facilities is even more pronounced. Other states of India, and other countries too, may probably echo this pattern of development of the health system over the coming decades. This challenges the EmOC recommendations as they stand at present, to consider refining or adding indicators to ensure well distributed and appropriate EmOC care, such as counting all facilities located within half a square kilometre as only one facility, or recommend numbers of purely midwife-led centres in a given population, respectively. These dimensions need to be further investigated and better understood in the context of saving maternal lives. Therefore, the guidelines for monitoring EmOC care as recommended by the WHO needs to address these field-level conditions so as to be able to refine and interpret the process indicators more accurately for the benefit of future maternal health policy and planning.

\section{Conclusions}

Public sector availability and provision of EmOC services are currently inadequate, much below the UN norms. However, in our setting, availability is dominated by the private sector, clustered in towns. Thus, it appears that for the present, purchasing emergency obstetric services from the private sector by the state is a pragmatic way to make it available for vulnerable populations. 
The health authorities of Gujarat can improve the availability of EmOC services cheaply, quickly and equitably if they would follow a two-pronged strategy of strengthening public EmOC in areas where no private provision exists and carefully selecting providers with assured BEmOC services into the CY programme to get the maximum benefit possible for vulnerable populations.

More refinement of UN recommended process benchmarks for EmOC care would be of great value to planners in mixed health systems.

\section{Handling editor Seye Abimbola}

Acknowledgements This study would not have been possible without the cooperation of the Gujarat state health department, particularly Dr NB Dholakia, and numerous private obstetricians. The authors would like to thank the EU FP7 programme which made this research possible. They would also like to thank reviewers of the previous version of their manuscript for their constructive comments.

Contributors DM, VI and KS conceived and designed the experiments. VI, KS and RM performed the experiments. VI and KS analysed the data. VI and KS wrote the manuscript. All authors reviewed the study protocol and results and discussed the analyses.

Funding The study was conducted as a part of the MATIND project which is financially supported by a grant under the European Union Framework Programme 7.

Competing interests None declared.

Provenance and peer review Not commissioned; externally peer reviewed.

Data sharing statement No additional data are available.

Open Access This is an Open Access article distributed in accordance with the Creative Commons Attribution Non Commercial (CC BY-NC 4.0) license, which permits others to distribute, remix, adapt, build upon this work noncommercially, and license their derivative works on different terms, provided the original work is properly cited and the use is non-commercial. See: http:// creativecommons.org/licenses/by-nc/4.0/

\section{REFERENCES}

1. Trends in Maternal Mortality: 1990 to 2013. Estimates by WHO, UNICEF, UNFPA, The World Bank and the United Nations Population Division. World Health Organisation, 2014. http://apps. who.int/iris/bitstream/10665/112682/2/9789241507226_eng.pdf? ua $=1$ (accessed 25 Jan 2016)

2. Campbell OM, Graham WJ. Strategies for reducing maternal mortality: getting on with what works. Lancet 2006;368:1284-99.

3. Maine D, Wardlaw TM, Ward VM, et al. Guidelines for monitoring the availability and use of obstetric services. Geneva: World Health Organization, 1997.

4. WHO, UNICEF, UNFPA and AMDD. Monitoring emergency obstetric care: a handbook. Geneva: World Health Organisation, 2009.

5. WHO, ICM, FIGO. Making pregnancy safer: the critical role of the skilled attendant. Geneva: World Health Organization, 2004.

6. Mavalankar D, Sankara Raman P, Vora K. Midwives of India: missing in action. Midwifery 2011;27:700-6.

7. Mavalankar DV, Rosenfield A. Maternal mortality in resource-poor settings: policy barriers to care. Am J Public Health 2005;95:200.

8. WHO. Health in 2015: from MDGs to SDGs: 2015. http://www.who. int/gho/publications/mdgs-sdgs/MDGs-SDGs2015_chapter1.pdf? ua $=1$ (accessed 25 Jan 2016).

9. Evans DB, Hsu J, Boerma T. Universal health coverage and universal access. Bull World Health Organ 2013;91:546-546A.

10. Paxton A, Bailey P, Lobis S, et al. Global patterns in availability of emergency obstetric care. Int J Gynaecol Obstet 2006;93:300-7.

11. Bailey P, Paxton A, Lobis $S$, et al. The availability of life-saving obstetric services in developing countries: an in-depth look at the signal functions for emergency obstetric care. Int J Gynaecol Obstet 2006;93:285-91.
12. District Level Household and Facility Survey (DLHS-3), 2007-08. IIPS/MoHFW. 2010.

13. RGI. Special bulletin on maternal mortality in India 2004-2006. New Delhi: Sample Registration System, 2009.

14. Mavalankar D, Singh A, Bhat R, et al. Indian public-private partnership for skilled birth-attendance. Lancet 2008;371: $631-2$.

15. Rodin J, de Ferranti D. Universal health coverage: the third global health transition? Lancet 2012;380:861-2.

16. Reddy KS, Patel V, Jha P, et al. Towards achievement of universal health care in India by 2020: a call to action. Lancet 2011;377:760-8.

17. Mavalankar D, Singh A, Patel SR, et al. Saving mothers and newborns through an innovative partnership with private sector obstetricians: Chiranjeevi scheme of Gujarat, India. Int J Gynaecol Obstet 2009;107:271-6.

18. Gujarat H. Gujarat human development report. Ahmedabad: Mahatma Gandhi Labour Institute, 2004.

19. Joshi V. The cultural context of development in Gujarat. In: Hirway I, Kashyap S, Shah A, eds. Dynamics of development in Gujarat. Ahmedabad: Concept Publishing Company, 2002:372-86. http:// www.in.undp.org/content/dam/india/docs/human_develop_report_ gujarat_2004_report.pdf

20. Census of India: provisional population totals-India data sheet. Office of the Registrar General Census Commissioner, India. Indian Census Bureau, 2011. http://pib.nic.in/prs/2011/latest31mar.pdf (accessed Jan 2016).

21. Vital statistics Division GoG. Civil Registration System in Gujarat, Annual Statistical Report 2010. Gandhinagar, 2011:5-6. http://www. gujhealth.gov.in/images/pdf/ASR_Work_Report_2010.pdf (accessed $15 \mathrm{Feb} 2016$, available on request).

22. Socio Economic Survey 2002-03. Add-on lists 2008-09 [database available online]. Gujarat: Commissionerate of Rural Development. http://ses2002.guj.nic.in/ (accessed 15 Feb 2016, available on request).

23. Mavalankar D, Vora KS. The changing role of auxiliary nurse midwife (ANM) in India: implications for maternal and child health $(\mathrm{MCH})$. Indian Institute of Management, 2008.

24. Prasad R, Dasgupta R. Missing midwifery: relevance for contemporary challenges in maternal health. Indian J Community Med 2013;38:9-14.

25. Government of Gujarat. Report of the committee to study backwardness of Talukas of Gujarat. Cowlagi V R S, Das P K, Dholakia A, Griwala B, Nambiar R G, Visaria L, Trivedi S. Gandhinagar, Gujarat. 2005.

26. Ameh C, Msuya S, Hofman J, et al. Status of emergency obstetric care in six developing countries five years before the MDG Targets for maternal and newborn health. PLOS ONE 2012;7:e49938.

27. Gabrysch S, Simushi V, Campbell OM. Availability and distribution of, and geographic access to emergency obstetric care in Zambia. Int J Gynaecol Obstet 2011;114:174-9.

28. Federation of Obstetric and Gynaecological Societies of India 23rd Annual Report and statement of accounts. Mumbai, India. 2013. http://www.fogsi.org/wp-content/uploads/2015/05/pdf/FOGSI_ Annual_Report_2012_13.pdf (accessed 15 Jun 2015).

29. Qureshi Z. Global monitoring report 2009: a development emergency. Global monitoring report. Washington, DC: World Bank, 2009.

30. Etienne C, Asamoa-Baah A, Evans DB. Health systems financing: the path to universal coverage. World Health Organization, 2010.

31. Evans CL, Maine D, McCloskey L, et al. Where there is no obstetrician-increasing capacity for emergency obstetric care in rural India: an evaluation of a pilot program to train general doctors. Int J Gynaecol Obstet 2009;107:277-82.

32. Raman P, Sharma B, Mavalankar D, Upadhyaya M. Assessing the regional and district capacity for operationalizing emergency obstetric care through First Referral Units in Gujarat. 2009. Working Paper No. 2009-04-01. Ahmedabad, India: Indian Institute of Management, 2009.

33. Sharma B, Mavalankar D. Health policy processes in Gujarat: A case study of the Policy for Independent Nurse Practitioners in Midwifery. 2012. Working Paper No. 2012-08-01. Ahmedabad, India: Indian Institute of Management, 2012.

34. Tierney JT, Waters WJ, Williams DC. Controlling physician oversupply through certificate of need. Am J Law Med 1980;6:335-60.

35. Battista RN, Banta HD, Jonnson $\mathrm{E}$, et al. Lessons from the eight countries. Health Policy 1994;30:397-421.

36. Gwatkin DR, Bhuiya A, Victora CG. Making health systems more equitable. Lancet 2004;364:1273-80. 
37. Gao Y, Barclay L. Availability and quality of emergency obstetric care in Shanxi Province, China. Int J Gynaecol Obstet 2010;110:181-5.

38. Saidu R, August EM, Alio AP, et al. An assessment of essential maternal health services in Kwara state, Nigeria: original research article. Afr J Reprod Health 2013;17:41-8.

39. Echoka E, Kombe $\mathrm{Y}$, Dubourg D, et al. Existence and functionality of emergency obstetric care services at district level in Kenya: theoretical coverage versus reality. BMC Health Serv Res 2013;13:113.

40. Mony PK, Krishnamurthy J, Thomas A, et al. Availability and distribution of emergency obstetric care services in Karnataka state, South India: access and equity considerations. PLOS ONE 2013;8:e64126.

41. Randive B, Chaturvedi S, Mistry N. Contracting in specialists for emergency obstetric care-does it work in rural India? BMC Health Serv Res 2012;12:485. 